\title{
Predicting Shear Strength in FRP-Reinforced Concrete Beams Using Bat Algorithm-Based Artificial Neural Network
}

\author{
Mohammad Nikoo $\mathbb{D}^{1},{ }^{1}$ Babak Aminnejad $(\mathbb{D})^{2}$ and Alireza Lork $\mathbb{D}^{3}$ \\ ${ }^{1}$ Department of Civil Engineering, Kish International Branch, Islamic Azad University, Kish Island, Iran \\ ${ }^{2}$ Department of Civil Engineering, Roudehen Branch, Islamic Azad University, Roudehen, Iran \\ ${ }^{3}$ Department of Civil Engineering, Safadasht Branch, Islamic Azad University, Tehran, Iran \\ Correspondence should be addressed to Babak Aminnejad; aminnejad@riau.ac.ir
}

Received 8 July 2021; Revised 22 September 2021; Accepted 1 November 2021; Published 16 December 2021

Academic Editor: Antonio Caggiano

Copyright (C) 2021 Mohammad Nikoo et al. This is an open access article distributed under the Creative Commons Attribution License, which permits unrestricted use, distribution, and reproduction in any medium, provided the original work is properly cited.

\begin{abstract}
In this article, 140 samples with different characteristics were collected from the literature. The Feed Forward network is used in this research. The parameters $f c(\mathrm{MPa}), \rho f(\%), E f(\mathrm{GPa}), \mathrm{a} / \mathrm{d}, \mathrm{bw}(\mathrm{mm}), d(\mathrm{~mm})$, and VMA are selected as inputs to determine the shear strength in FRP-reinforced concrete beams. The structure of the artificial neural network (ANN) is also optimized using the bat algorithm. ANN is also compared to the Genetic Algorithm (GA) and Particle Swarm Optimization (PSO) algorithm. Finally, Nehdi et al.'s model, ACI-440, and BISE-99 equations were used to evaluate the models' accuracy. The results confirm that the bat algorithm-optimized ANN is more capable, flexible, and provides superior precision than the other three models in determining the shear strength of the FRP-reinforced concrete beams.
\end{abstract}

\section{Introduction}

The steel bars are widely employed to enhance durability in concrete structures [1]. However, they are vulnerable to corrosion in acidic and alkaline environments [2]. Therefore, engineers have developed and utilized Fiber Reinforced Polymer (FRP) rebars to remedy this situation while offering further benefits to the design by replacing conventional steel bars and preventing corrosion in susceptible environments [3]. In this sense, the FRP rebars are suitable solutions for concrete reinforcement [1].

Abdalla et al. predicted the shear strength in the rectangular R/C beams using ANNs by employing six parameters: beam depth, beamwidth, span-to-depth ratio, longitudinal reinforcement, shear reinforcement, and concrete strength as the ANN inputs. In addition, they compared the obtained shear strength results with the ACI318-02 and BS8110 codes. The results showed that ANN offered accurate predictions for the shear strength of rectangular R/ C beams.

Nehdi et al. presented a set of GA-optimized equations to calculate the shear strength of the FRP-reinforced concrete beams and compared them with the methods outlined in the ACI 440, CSA S806, JSCE, and ISIS (Canada) codes. They found that the strategies proposed for computing shear strength in the FRP-reinforced concrete beams are insufficient or very conservative. Also, Nehdi et al. utilized the GA and developed a set of simple equations to determine the shear strength of the FRP-reinforced concrete beams. The results of examining 212 experimental samples revealed that the shear span-to-depth ratio influences shear behavior in the bonded-FRP-reinforced concrete beams [4]. In addition, various other scholars, including Ricardo Perera et al. and Shahnewaz et al., conducted studies on GA to determine the shear strength equations. Kara optimized GA to determine the shear strength of concrete beams. In another study, Shahnewaz et al. used a database comprising 162 experiments on the FRP beams with and without straps and optimized the equations using GA. They established that the proposed equations are more accurate than the equations provided in the previous building codes [5]. Instead of using multiple linear regression models, Perera et al. used ANN to predict the shear strength in reinforced concrete beams. Also, they presented a parametric study to determine 
the effects of some parameters of the beam and external reinforcement on shear strength to achieve reliable designs. They established that the ANN model is superior to the building code guidelines [6]. In another article, Perera et al. used neural networks to predict the shear strength by simultaneously testing the experimental data in simple FRPreinforced beams and compared the results [7].

Tanarslan et al. used 84 concrete beam samples to determine shear strength in the presence of FRP and presented ANN for modeling. They compared the results with several building codes, including fib14, ACI 440.2R, CIDAR, CNRDT 200, and CHBDC. The results showed that the ANN models presented better accuracy than the codes [8]. Using ANNs, Jalal and Ramezanianpour determined the ultimate strength in carbon fiber reinforced polymers (CFRPs) [9]. Mozumder et al. determined the compressive strength of concrete using Support Vector Machine Regression, compared the proposed model with ANNs, and performed a sensitivity analysis on selecting effective input parameters. The study showed that SVR could be used as a powerful alternative physical tool for predicting FRP-confined concrete strength [10].

Chahnasir et al. determined the shear strength of the FRP-reinforced concrete beams using a support vector machine and the firefly algorithm. They compared the proposed model with an ANN combined with a genetic algorithm [11]. Safa et al. showed that the firefly algorithm could reduce error in the proposed model and measure the compressive strength of concrete with high accuracy. Chou et al. used the intelligent firefly algorithm (IFA) to optimize the support vector machine model's weights. As a result, they established that the proposed model is highly accurate [12]. Finally, Zhang and Wang used the beetle antennae search (BAS) algorithm combined with SVM, which has a high accuracy of $R^{2}=0.938$. They also showed that FRP width is the most sensitive variable in beam shear strength [13].

Abuodeh et al. studied the behavior of reinforced concrete (RC) beams and determined the shear strength in the FRP-reinforced state using machine learning. They used a 120-sample dataset with 15 different variables. They utilized the resilient backpropagation algorithm for modeling the recursive feature elimination (RFE) algorithm to optimize weights and used the sensitivity analysis to reduce the parameters. The results showed that the Radial Basis Probabilistic Neural Network (RBPNN) with the selected parameters accurately predicted the shear capacity of FRP $\left(R^{2}=0.885\right)[14]$. Also, in a study, Kamkar et al. determined a new formula for determining the shear capacity of FRP beams [15].

Naderpour et al. used various methods, including ANNs, gene expression programming, and group method of data handling, to predict the compressive strength of FRP-confined columns. Their model constituted 95 experimental data. The input parameters included column height, concrete compressive strength, FRP elastic modulus, yield strength, the area of longitudinal steel, and FRP and transverse steel confining pressure. Also, they compared the results with the formulas provided in the national and international building codes in which the ANN model presented superior accuracy [16]. Naderpour et al. used an ANN model to develop a novel equation for predicting the shear strength of FRP-reinforced concrete beams. For this purpose, 120 experimental data were used. In addition, the sensitivity analysis was conducted to examine the input parameters' effects on the outputs. The results showed that the presented equation offers better results with higher accuracy than the other relations [12]. Naderpour et al. also determined the shear strength of FRP bars using artificial neural networks [17].

Cao et al. used six input parameters representing the bars' geometric and mechanical properties and shear properties. Then, utilizing the adaptive neural fuzzy inference system (ANFIS), they compared the shear strength of FRP-reinforced concrete beams. They established that the shear span-to-depth ratio parameter had the most significant effect in predicting the shear strength of FRPreinforced concrete beams. They also showed that the tensile reinforcement depth, FRP tensile modulus, and the shear span-to-depth ratio are the leading influential parameters in predicting the shear strength of FRP-reinforced concrete beams [18]. Kar et al. determined the shear strength of the RC beams using an adaptive neuro-fuzzy inference system [19]. Alam and Gazder proposed a generalized regression neural network (GRNN)-based model to predict the shear strength of FRP-reinforced concrete without transverse reinforcement. They used 196 laboratory samples and compared the model's accuracy with the JSCE, CSA S806, ACI 440.1R, and BISE building codes. The proposed model exhibited superior accuracy compared to the building codes [20].

Many opportunities exist in civil engineering to develop models using novel optimization techniques. The bat optimization algorithm is a metaheuristic algorithm inspired by bats' behavior. It has performed more successfully than other metaheuristic algorithms [21]. The study emphasizes increasing the prediction model's ability using the bat algorithm to train ANN. Another advantage of this paper is the use of the bat algorithm to optimize weights in artificial neural networks to reduce the error rate and increase the model's accuracy. This algorithm can be used as a powerful tool. The proposed method reflects all critical parameters required to predict the shear strength of FRP-reinforced concrete beams and analyzes them using a database of 140 samples.

The remainder of the present paper is as follows: Section 2 offers a thorough contextual review of artificial neural networks and the bat algorithm. Section 3 offers information about the experimental model's development and training. Finally, sections 4 and 5 present the results and conclusion of the study. Figure 1 shows the process of using the bat algorithm in neural networks.

\section{Background}

2.1. Artificial Neural Networks. Artificial neural networks (ANNs) are among the most dynamic areas of current research [22]. The features and capabilities of neural networks 


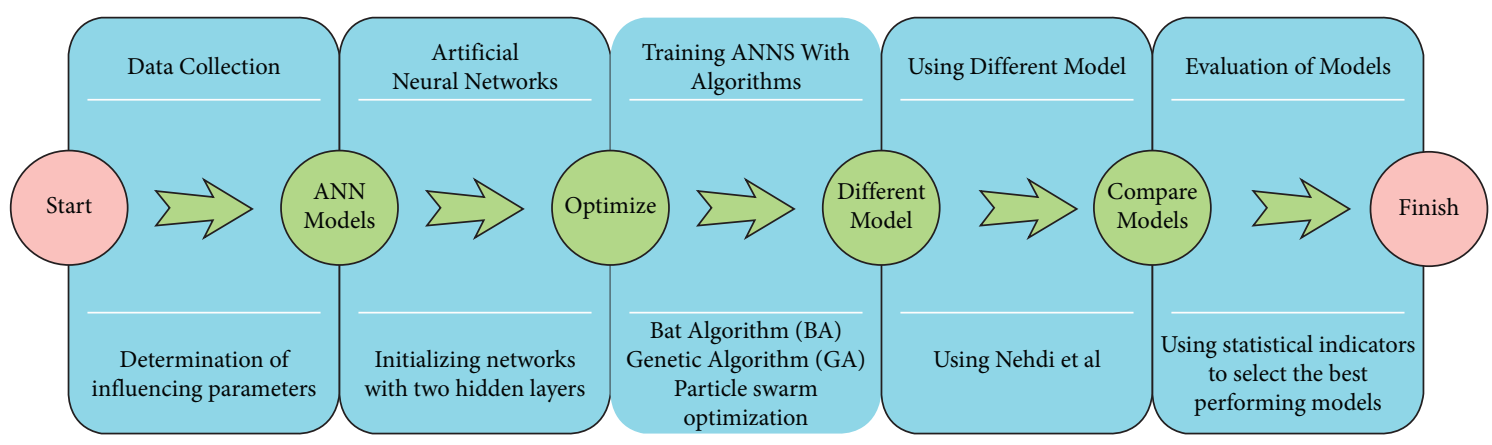

FIgUre 1: Outline of the paper.

include learning and adapting to existing knowledge, generalizability, higher processing speed, and error reduction [23]. For example, Figure 2 demonstrates a neural network with six neurons in the input layer, two hidden layers comprising twelve and five neurons, and a single output layer. According to Fan et al. [24], ANNs are based on the following processes:

(1) Data are processed in units called neurons (or nodes).

(2) Signals between the nodes are transmitted through connection lines.

(3) The weight of each connection indicates its strength.

(4) An activation function is applied to the weight input (plus the bias value) to determine the output of each neuron [24]. The feed-forward network is an ANN model in which the connection between its components does not create a cycle. The data flows from the input nodes through the hidden layers to the output nodes [25].

ANN network weights are usually assigned arbitrarily. The network output will be different from the target values. The network weights and deviations must be optimized in a neural network process to minimize the model error [26-28]. The methods for solving this optimization problem can be divided into gradient-based methods and metaheuristic methods. Contrary to the metaheuristic methods, the gradient-based approaches may be a constraint in local minima. Meanwhile, the drawback of the metaheuristic methods is that their solution is not necessarily universal. Nevertheless, they are typically intended to discover, exploit, and provide accurate results $[26,27,29]$.

2.2. Bat Algorithm. The bat optimization algorithm is inspired by the tracking characteristics of small bats hunting prey in complete darkness by sending and receiving sound. In addition, the bat algorithm is based on the mammal's impressive echolocation behavior. The microbats' echolocation ability helps them identify their prey in total darkness and distinguish between different insects [30, 31].

If we thoroughly identify some of the echolocation features of microbats, we can present different algorithms derived from bats and use them for the following approximate rules [32]:

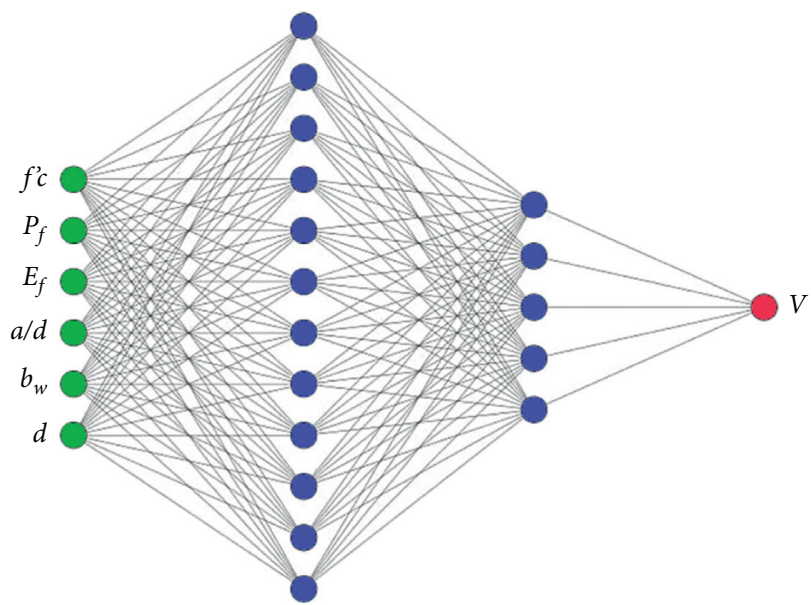

FIgURE 2: The architecture of the ANN proposed for study using six input neurons, twelve and five neurons in two hidden layers, and a single output neuron in the output layer.

(1) Bats utilize echolocation to detect direction and distance. They differentiate between prey, food, and other obstacles.

(2) Bats fly arbitrarily in search of prey with a velocity $(v)$ at a position $(x)$ with a fixed frequency $(f)$, variable wavelengths $(\lambda)$, and loudness $\left(A_{0}\right)$. Their proximity to the target can easily distinguish their emitted wavelength or pulse when $r \in[0,1]$.

(3) Though the bats' loudness may vary, we suppose their loudness deviates from a large $A_{0}$ favorable position to a minimum constant value [32].

In a rather precise real-world execution, the amplitude is adjusted by changing the wavelengths. The identifiable range (in other words, the largest wavelength) must be selected as comparable to the desired amplitude, and then, it must be reduced to lower frequencies. Also, we are not limited to using the bats' actual frequencies. Instead, we can change the frequencies when adjusting the wavelength $f_{0}$. Because $f_{\max }$ and $f_{\min }$ are relative to each other, we use them in our assumption. We can choose $f \in[0, f \max ]$. The higher frequencies correspond to shorter wavelengths, thus traveling shorter distances. The normal range for bats is a few meters. The pulse rate is in the range of $[0,1]$, with 0 denoting no pulse and 1 signifying the average maximum pulse rate [30, 33]. 


\section{Materials and Methods}

3.1. Dataset. The database in this article is derived from the dataset collected by Hasanzade-Inallu et al. It comprises 140 experimental results of shear strength in the FRP-reinforced concrete beams gathered by Hasanzade-Inallu et al. [21]. In this paper, the input and independent parameters in each sample, including $f^{\prime} c(\mathrm{MPa}), \rho f(\%), E f(\mathrm{GPa}), \mathrm{a} / \mathrm{d}$, bw $(\mathrm{mm})$, and $d(\mathrm{~mm})$ form a $6 \times 1$ matrix, and the dependent parameter consists of $\mathrm{Vcf}(\mathrm{kN})$, which forms a $1 \times 1$ matrix. Table 1 shows the statistical characteristics of the data.

Different input variables in an ANN can have adverse effects on a model, such as a divergence optimization algorithm and an increased training time [27]. Therefore, the dataset's input and output variables can be normalized within the $[-1,1]$ range. According to Hasanzade-Inallu et al., normalization is presented as equation (1). [21]

$$
X_{n}=\frac{2\left(X-X_{\min }\right)}{X_{\max }-X_{\text {mix }}}-1,
$$

where $X_{n}=$ normalized variable, $X_{\max }=$ maximum value, $X_{\min }=$ minimum value, and $X=$ original (nontransformed) variable value.

Table 1 provides the minimum and maximum values for each of the six input parameters and the shear strength target value. According to Hasanzade-Inallu et al., considering ANN training is based on the normalized data, the normalized values of the variables must be fed to the network using ANN to predict the new values and transfer the outputs of the network to their original (unnormalized) state [21].

The probability plot [34] inspects the normality of critical parameters within the data. These plots are shown in Figures 3 and 4 . According to the outputs, the shear strength has a distribution close to the normal distribution, which indicates the suitability of the dataset for modeling.

3.2. Performance Measures. Assessing the performance and accuracy of the model requires us to define the criteria for such measurements. The goal is to define the best fitness value (or the lowest cost) in the test data, thereby selecting the model with the highest reliability and accuracy [35]. The statistical indices, including Mean Error (ME), Mean Absolute Error (MAE), Mean Squared Error (MSE), Root Mean Squared Error (RMSE), Average Absolute Error (AAE), Model Efficiency (EF), and Variance Account Factor (VAF) are used to assess the performance of various topologies $[35,36]$ as follows:

$$
\begin{aligned}
\mathrm{ME} & =\frac{1}{n} \sum_{i=1}^{n}\left(P_{i}-O_{i}\right), \\
\mathrm{MAE} & =\frac{1}{n} \sum_{i=1}^{n}\left|P_{i}-O_{i}\right|, \\
\mathrm{MSE} & =\frac{1}{n} \sum_{i=1}^{n}\left(P_{i}-O_{i}\right)^{2},
\end{aligned}
$$

TABLE 1: Statistical characteristics of the data [21].

\begin{tabular}{lccccc}
\hline Statistical index & Type & Max & Min & Average & STD \\
\hline$f c(\mathrm{MPa})$ & Input & 88.30 & 22.70 & 40.97 & 11.95 \\
$\rho f(\%)$ & Input & 3.02 & 0.18 & 1.06 & 0.60 \\
$E f(\mathrm{GPa})$ & Input & 192.00 & 23.20 & 59.00 & 43.06 \\
$\mathrm{a} / \mathrm{d}$ & Input & 8.44 & 1.00 & 3.24 & 1.37 \\
$\mathrm{bw}(\mathrm{mm})$ & Input & 1000.00 & 114.00 & 283.81 & 198.98 \\
$d(\mathrm{~mm})$ & Input & 1097.00 & 141.00 & 338.95 & 221.22 \\
$\mathrm{Vcf}(\mathrm{kN})$ & Output & 953.00 & 13.97 & 100.76 & 129.78 \\
\hline
\end{tabular}

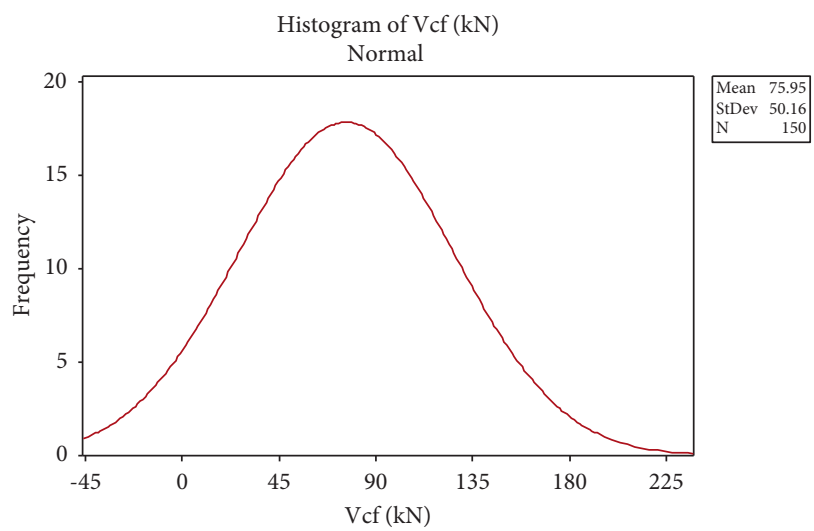

FIgURE 3: Normal distribution of shear capacity in FRP-reinforced concrete beams.

$$
\begin{aligned}
\mathrm{RMSE} & =\left[\frac{1}{n} \sum_{i=1}^{n}\left(P_{i}-O_{i}\right)^{2}\right]^{1 / 2}, \\
\mathrm{AAE} & =\frac{\left|\sum_{i=1}^{n}\left(\left(O_{i}-P_{i}\right) / O_{i}\right)\right|}{n} \times 100, \\
\mathrm{EF} & =1-\frac{\sum_{i=1}^{n}\left(P_{i}-O_{i}\right)^{2}}{\sum_{i=1}^{n}\left(\bar{O}_{i}-O_{i}\right)^{2}}, \\
\mathrm{VAF} & =\left[1-\frac{\operatorname{var}\left(O_{i}-P_{i}\right)}{\operatorname{var}\left(O_{i}\right)}\right] \times 100 .
\end{aligned}
$$

3.3. Developing an Empirical Model Using BAT and ANNs. According to Section 3.1, six parameters influence the shear strength of the FRP-reinforced concrete beams. Hence, as shown in Figure 2, the trained ANNs have six neurons in their input layer and a single neuron in their output layer.

ANNs are vulnerable to overfitting, which means that the trained ANN network offers high performance (minimum data error during training). Yet, it fails to perform well when experimental data are not observed. Therefore, two random datasets were formed to minimize the over-installation effects as suggested in the literature [21, 26]. Ninety-eight samples $(70 \%)$ were used for network training, and the remaining 30\% (42 samples) were used for network performance testing. The ANN model is assigned with a specific number of hidden layers and total neurons in the 


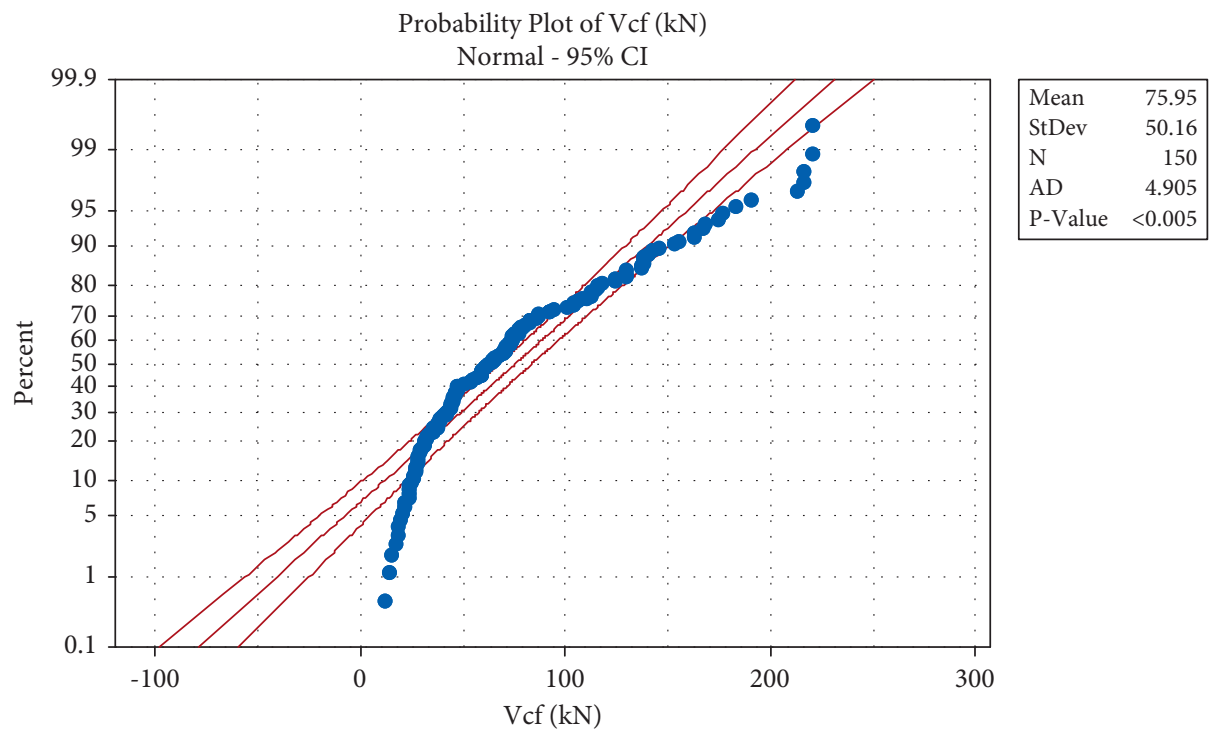

FIgURE 4: P-P plot of shear capacity in FRP-reinforced concrete beams.

corresponding hidden layers based on the problem type. The ideal architecture, which better represents the problem data, was obtained by trial and error. Equation (3) offers a conventional heuristic method that determines the total number of neurons in ANN [37]:

$$
N_{H} \leq 2 N_{I}+1,
$$

where $N_{H}$ represents the number of hidden layer nodes, and $N_{I}$ is the number of inputs. Considering the six effective parameters (inputs), the empirical equation indicates 13 hidden layer nodes.

Therefore, different architectures had two trained hidden layers and a maximum of 13 neurons (three neurons more than the recommended value). For example, in the two-layer model, the first hidden layer had 1 to 13 neurons, and the second hidden layer had 1 to 13 neurons. Hence, the models had 169 different trained architectures (Table 2).

For all ANNs, the hyperbolic tangent function ( $\tanh$ ) is the hidden layer activation function, whereas the identity function is chosen as the output layer activation function. A well-adjusted ANN is obtained by training the model and minimizing the error so that the optimal solution's weight and bias minimize the cost performance (network prediction error). The bat algorithm defined in Section 2.2 was used for this purpose. To show weight and bias, ANN provides the least predictive error for trained architecture.

MATLAB version 2018 software was used to program the ANNs and BAT algorithms. The BAT training parameters of the 169 ANNs are provided in Table 3.

\section{Results}

4.1. Evaluating the Empirical Model. As explained in Section 3, the bat algorithm was used to train 169 different two-layer ANN architectures. The hyperbolic tangent function (tanh) was chosen as the activation function for the hidden layers. Meanwhile, the activation function of the output layer was
TABLE 2: Trained ANN architectures.

\begin{tabular}{lcccccc}
\hline Num & Topology & Num & Topology & $\ldots$ & Num & Topology \\
\hline 1 & $1-1$ & 12 & $2-1$ & $\ldots$ & 157 & $13-1$ \\
2 & $1-2$ & 13 & $2-2$ & $\ldots$ & 158 & $13-2$ \\
3 & $1-3$ & 14 & $2-3$ & $\ldots$ & 159 & $13-3$ \\
4 & $1-4$ & 15 & $2-4$ & $\ldots$ & 160 & $13-4$ \\
$\ldots$ & $\ldots$ & $\ldots$ & $\ldots$ & $\ldots$ & $\ldots$ & $\ldots$ \\
12 & $1-12$ & 25 & $2-12$ & $\ldots$ & 168 & $13-12$ \\
13 & $1-13$ & 26 & $2-13$ & $\ldots$ & 169 & $13-13$ \\
\hline
\end{tabular}

TABLE 3: The BAT algorithm parameters.

\begin{tabular}{lccc}
\hline Parameter & Value & Parameter & Value \\
\hline Population size & 100 & Max generations & 200 \\
Loudness & 0.9 & Pulse rate & 0.5 \\
Minimum frequency & 0 & Maximum frequency & 2 \\
Alpha & 0.99 & Gamma & 0.01 \\
\hline
\end{tabular}

chosen as the model's identity function. From the 169 models trained for predicting the shear strength in the FRPreinforced concrete beams, six of the best models were selected based on their mean squared error (MSE) values. Tables 4 and 5 present the chosen models and their test results.

According to the tables, ANN 2L (12-5) has the minimum MSE and RMSE values for data training and testing. The ANN-BAT 2L (5-12) network has the lowest MSR index, indicating better generalizability and accuracy. Also, the neural network function is compatible with training and testing. Therefore, it was selected as the best model trained using the BAT algorithm for further analyses. The ANNBAT 2L (5-12) network training data has the RMSE and $R$ values of 12.993 and 0.995 , respectively. Also, the RMSE and $R$ values for the test phase are 43.987 and 0.987 , respectively. The data training and testing error criteria are computed by data values within the variables' main range instead of their normalized $[-1,+1]$ range as seen in some other studies. 
TABLE 4: Statistics of the top six ANNs on training data.

\begin{tabular}{lccccc}
\hline Num & Network designation & MSE & $R$ & ME & MAE \\
\hline 1 & ANN-bat 2L (12-5) & 168.827 & 0.995 & 0.044 & 8.794 \\
2 & ANN-bat 2L (10-4) & 212.977 & 0.993 & 0.040 & 10.013 \\
3 & ANN-bat 2L (7-3) & 334.240 & 0.989 & -0.261 & 13.341 \\
4 & ANN-bat 2L (9-3) & 583.266 & 0.982 & 0.118 & 14.993 \\
5 & ANN-bat 2L (8-5) & 637.162 & 0.980 & -0.700 & 18.766 \\
6 & ANN-bat 2L (10-4) & 296.139 & 0.991 & -0.107 & 19.550 \\
\hline
\end{tabular}

The predicted and experimental values are shown in Figures 5-7 to illustrate the ANN-Bat 2L (12-5) model's performance. The model predictions are plotted near the $y=x$ line, which signifies the models' accuracy.

4.2. Model Comparisons. Three different models have been developed to assess the bat algorithm ANN-training for predicting the shear strength of concrete beams (KN). The ANNs underwent training using GA, PSO, and the Nehdi et al. model [38].

4.2.1. Particle Swarm Optimization. The same 169-member architecture provided in Table 2 was employed to train the ANNs using PSO to identify the top-performing ANN architecture. The top-performing ANN had nine neurons in the first hidden layer and three neurons in the second hidden layer. Henceforth, the networks will be denoted as ANNPSO 2L (9-3) to differentiate between ANNs trained using BAT and PSO.

The PSO parameters employed for training ANN-PSO 2L (9-3) were obtained using trial and error (Table 6). The PSO ANN has a much higher prediction error compared to the BAT-ANN. The predicted values for the shear strength of concrete beams $(\mathrm{KN})$ versus their experimental values are depicted in Figure 8 to illustrate the model's performance. The points plotted on the graph are distanced from the $y=x$ line compared to ANN-BAT 2L (12-5).

4.2.2. Genetic Algorithm. The 169-architecture provided in Table 2 is employed to find the ANN architecture with superior performance. In addition, the Genetic Algorithm is used as a helpful tool to optimize the neural networks. ANNGA 2L (7-3) was the best network comprising two hidden layers and nine nodes in the first layer and three nodes in the second layer.

The ANN-GA 2L (7-3) model's optimization training parameters were obtained by trial and error (Table 7). Compared to the BAT ANN, ANN-GA 2L (7-3) has a less accurate prediction error. The predicted shear strength values of the concrete beams (KN), as opposed to their test values, are shown in Figure 9 to visualize the model's performance. The points on the plot are farther away from the $y=x$ line.

4.2.3. The Experimental Model by Nehdi et al [38]. The batoptimized ANN model was compared with the experimental model by Nehdi et al. The characteristics of their model are shown in equation (4) $[4,39]$.

$$
\begin{aligned}
& \text { if } \frac{a}{d} \geq 2.5 \quad V_{c}=2.1\left(\frac{f_{c}^{\prime} \rho_{f} d}{a} \times \frac{E_{f}}{E_{s}}\right)^{0.23} \mathrm{bd}, \\
& \text { if } \frac{a}{d}<2.5 V_{c}=2.1\left(\frac{f_{c}^{\prime} \rho_{f} d}{a} \times \frac{E_{f}}{E_{s}}\right)^{0.23} \mathrm{bd} \times \frac{2.5 d}{a} .
\end{aligned}
$$

The equation results for all samples are shown in Figure 10. According to the results, the ANN-Bat model offers better results.

4.2.4. The Experimental Model by ACI 440.1R-15 and $B I S E-99$. To better evaluate the model, it is compared with the two standard codes ACI 440.1R-15 and BISE-99. The characteristics of ACI 440.1R-15 model are shown in equation (5). [40]. Also, the characteristics of BISE-99 model are shown in equation (5) $[41,42]$.

$$
\begin{aligned}
& V_{c}=\frac{2}{5} \sqrt{f_{c}^{\prime}} b_{w}(k d), k=\sqrt{2 \rho_{f} n_{f}+\left(\rho_{f} n_{f}\right)^{2}}-\rho_{f} n_{f} \text { and } n_{f}=\frac{E_{f}}{E_{c}} . \\
& E_{c}=4700 \sqrt{f_{c}^{\prime}} \text { for normal weight concrete. } \\
& V_{c}=0.79\left(100 \rho_{f} \frac{E_{f}}{E_{s}}\right)^{1 / 3}\left(\frac{400}{d}\right)^{0.25}\left(\frac{f_{c u}}{25}\right)^{1 / 3} b_{w} d, \frac{400}{d} \leq 1 .
\end{aligned}
$$

The equation results for all samples are shown in Figures 11 and 12. According to the results, the ANN-Bat model offers better results.

The MAE, RMSE, AAE, and VAF statistical indices of the studied models for the train, test, and all data modes are provided in Table 8 . Based on the results, the ANN-Bat $2 \mathrm{~L}$ (12-5) offers superior results, followed by the ANN-PSO 2L (9-3), ANN-GA 2L (7-3), ACI-440, BISE-99, and the Nehdi et al. model, respectively.

Figure 13 illustrates the predictions of the models using test data.

Taylor diagrams are accurate diagrams designed to show several models for comparison. This diagram, designed by Karl E. Taylor in 1994 [43], is used to quantify the degree of conformity between the modeled and observed behavior in terms of three statistics: the Pearson correlation coefficient, the root-mean-square error (RMSE) error, and the standard deviation [43]. As shown in Figure 14, the Taylor diagram is another suitable visual measure to be considered when comparing the performance of ANN-Bat against other 
Table 5: Statistics of the Top 10 ANNs based on the test data.

\begin{tabular}{|c|c|c|c|c|c|c|}
\hline Num & Network designation & MSE & $R$ & $\mathrm{ME}$ & MAE & RMSE \\
\hline 1 & ANN-bat 2L (12-5) & 1934.757 & 0.987 & 8.020 & 23.602 & 43.986 \\
\hline 2 & ANN-bat 2L (10-4) & 3146.645 & 0.973 & 17.807 & 30.538 & 56.095 \\
\hline 3 & ANN-bat 2L (7-3) & 3309.031 & 0.966 & 14.047 & 32.031 & 57.524 \\
\hline 4 & ANN-bat 2L (9-3) & 2910.475 & 0.958 & 11.828 & 34.168 & 53.949 \\
\hline 5 & ANN-bat 2L (8-5) & 3959.096 & 0.950 & 15.291 & 37.785 & 62.921 \\
\hline 6 & ANN-bat 2L (10-4) & 9105.949 & 0.918 & 26.401 & 45.563 & 95.425 \\
\hline
\end{tabular}

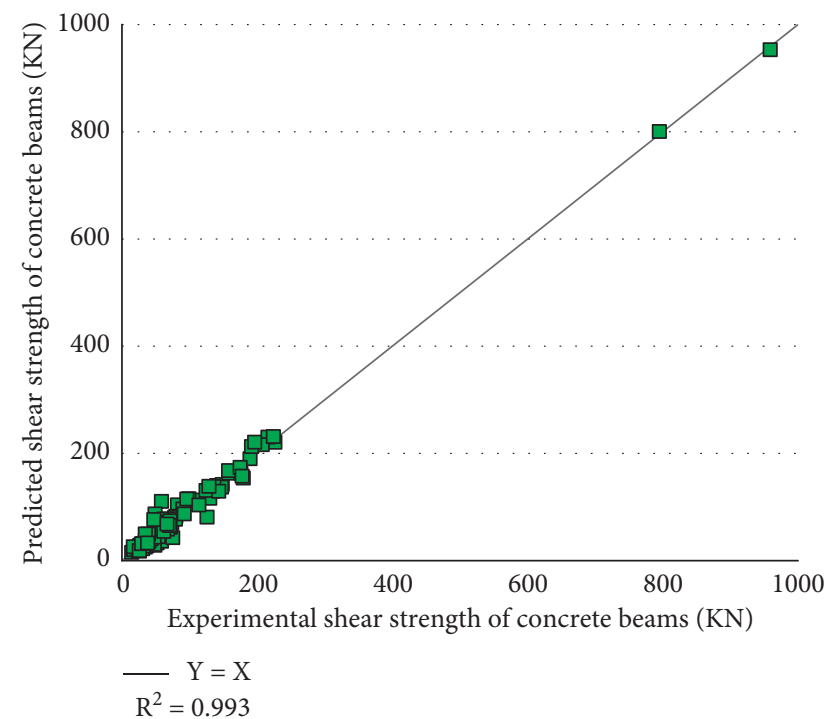

FIGURE 5: Experimental vs. predicted values of the shear strength of concrete beams (KN) for the ANN-BAT (12-5) model using training data.

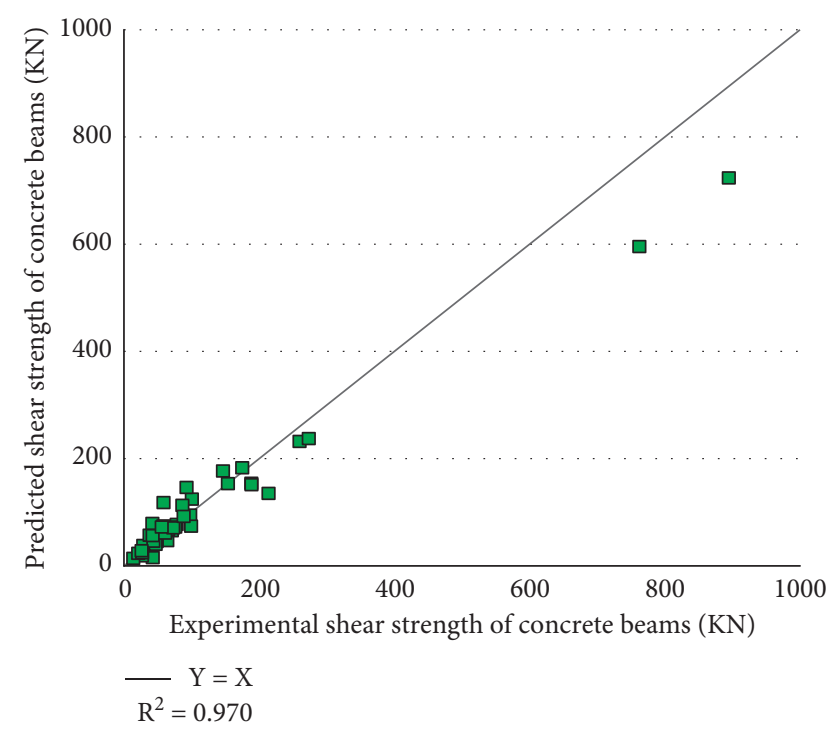

FIGURE 6: Experimental vs. predicted values of the shear strength of concrete beams $(\mathrm{KN})$ for the ANN-BAT (12-5) model using test data.

models. It offers a graphical illustration of each model's adequacy based on the RMSE, correlation coefficient, and standard deviation (SD) [44].

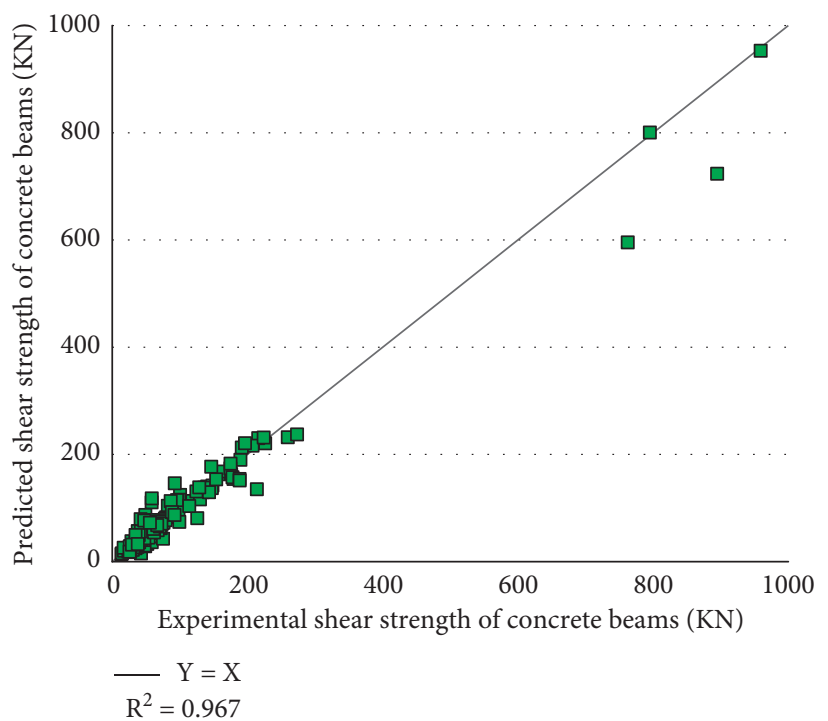

FIGURE 7: Experimental vs. predicted values of the shear strength of concrete beams $(\mathrm{KN})$ for the ANN-BAT (12-5) model using all data.

4.3. Predictive Model with ANN Weights and Sensitivity Analysis. ANN-Bat 2L (12-5) is considered the best experimental model presented in this study. However, the ANN-BAT model works only if the source file is accessible to the researchers. Hence, the network's weight and bias values are provided in this section. As noted previously, the networks' input data must initially be normalized using equation (1). For this purpose, Table 1 offers the maximum and minimum values for each of the variables. Subsequently, the output should be restored to its original state. The input is the $6 \times 1$ vector $a^{(1)}$. The shear strength of the concrete beam is calculated according to the following equations [21]:

$$
\begin{aligned}
a^{(2)} & =\tanh \left(I W \times a^{(2)}+b_{1}\right), \\
a^{(3)} & =\tanh \left(L W 1 \times a^{(2)}+b_{2}\right), \\
Y_{V c}^{\text {Predic (Normalize) }} & =\tanh \left(L W 2 \times a^{(3)}+b_{3}\right), \\
Y_{V c}^{\text {Predict (Actual) }} & =\frac{Y_{V c}^{\text {PredictNormalize }}+1}{2} \times\left(Y_{\text {max }}-Y_{\text {min }}\right)+Y_{\text {min }},
\end{aligned}
$$

where, according to Table 1, tanh $=$ Hyperbolic tangent function, $f^{\text {predicted }}=$ Predicted value of compressive strength, 
TABLE 6: The PSO parameters.

\begin{tabular}{lccccc}
\hline Parameter & Value & Parameter & Value & Parameter & Value \\
\hline Lowe bound & -1 & Swarm size & 200 & C1 & 2 \\
Upper bound & +1 & Max iterations & 150 & C2 & 2 \\
\hline
\end{tabular}

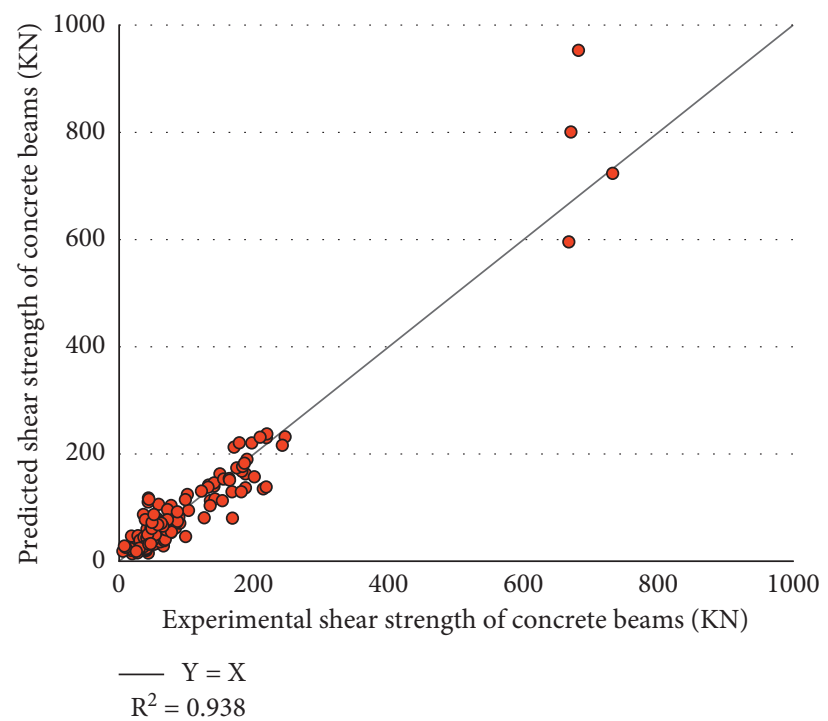

FIGURE 8: Experimental vs. predicted values of the shear strength of concrete beams (KN) for the ANN-PSO (9-3) model using all data.

TABLE 7: Genetic Algorithm parameters.

\begin{tabular}{lcccccc}
\hline Parameter & Value & Parameter & Value & Parameter & Value & Parameter \\
\hline Lowe bound & -1 & Selection mode & 1 & Max generations & 100 & Cross over percent \\
Upper bound & +1 & Population size & 150 & Recombination percent & 15 & \\
\hline
\end{tabular}

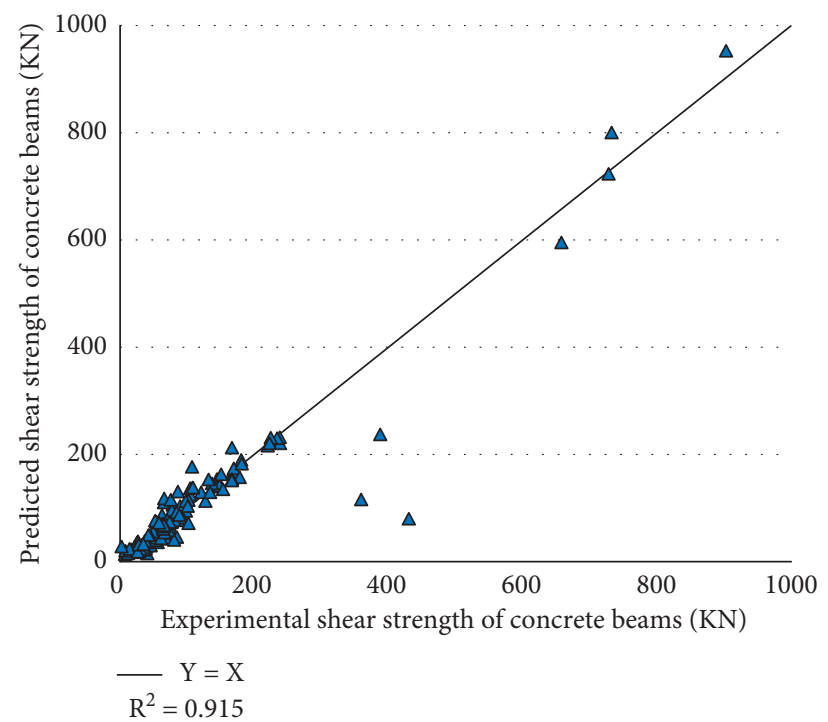

FIGURE 9: Experimental vs. predicted values of the shear strength of concrete beams (KN) for the ANN-GA (7-3) model using all data.

$f_{\max }=$ Maximum shear strength of concrete beam $(\mathrm{KN})$, and $f_{\text {min }}=$ Maximum shear strength of concrete beam $(\mathrm{KN})$.

The parameters IW, LW1, LW2, b1, b2, and b3 are shown as vector matrices in Table 9.
The sensitivity analysis assesses the impact of different input parameters over their entire spatial area and measures the uncertainty of output caused by input uncertainty, either over communication with other parameters or taken 


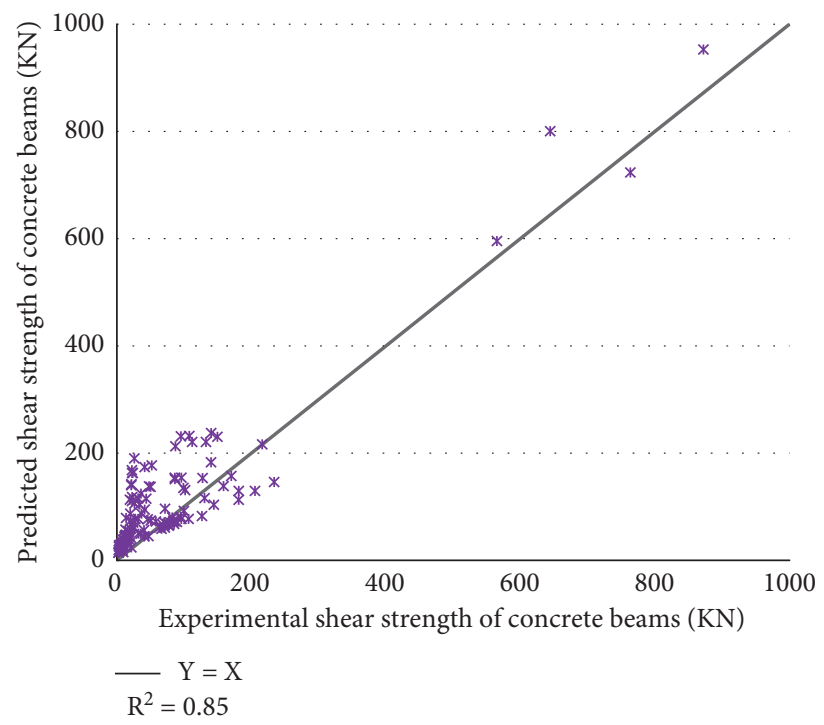

FIGURE 10: Experimental vs. predicted values of the shear strength of concrete beams (KN) for the Nehdi et al. model using all data.

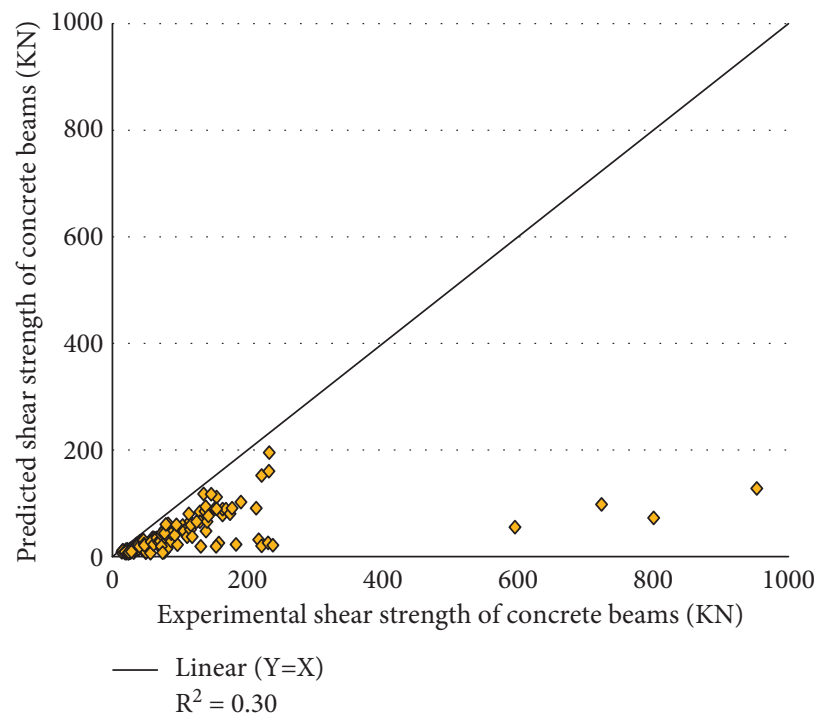

FIgURE 11: Experimental vs. Predicted values of the shear strength of concrete beams (KN) for the ACI 440 model using all data.

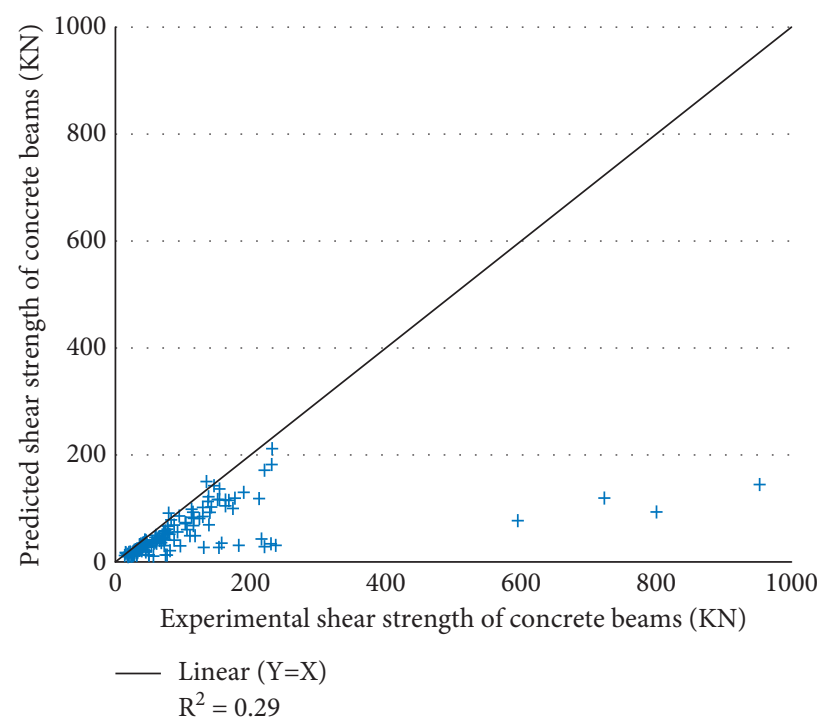

FIgURe 12: Experimental vs. Predicted values of the shear strength of concrete beams (KN) for the BISE-99 model using all data. 
TABLE 8: Statistical indices of the different models.

\begin{tabular}{|c|c|c|c|c|c|c|c|c|c|c|c|c|}
\hline \multirow{2}{*}{ Topology } & \multicolumn{4}{|c|}{ Train } & \multicolumn{4}{|c|}{ Test } & \multicolumn{4}{|c|}{ All } \\
\hline & MAE & RMSE & AAE & VAF (\%) & MAE & RMSE & AAE & VAF (\%) & MAE & RMSE & AAE & VAF (\%) \\
\hline ANN-bat 2L (12-5) & 8.79 & 12.99 & 0.15 & 0.99 & 23.60 & 43.99 & 0.22 & 0.90 & 13.24 & 26.43 & 0.17 & 0.96 \\
\hline ANN-GA 2L (7-3) & 18.05 & 46.48 & 0.26 & 0.87 & 17.67 & 31.30 & 0.24 & 0.95 & 17.93 & 42.50 & 0.26 & 0.89 \\
\hline ANN-PSO 2L (9-3) & 23.36 & 40.01 & 0.32 & 0.90 & 17.35 & 25.80 & 0.27 & 0.97 & 21.56 & 36.34 & 0.30 & 0.92 \\
\hline Nehdi et al. & 43.39 & 59.12 & 0.54 & 0.86 & 39.60 & 50.62 & 0.48 & 0.90 & 42.26 & 56.70 & 0.53 & 0.87 \\
\hline ACI 440 & 58.41 & 125.05 & 0.55 & 0.24 & 69.39 & 140.58 & 0.53 & 0.18 & 61.70 & 129.90 & 0.54 & 0.22 \\
\hline BISC-99 & 46.25 & 118.41 & 0.38 & 0.26 & 57.58 & 133.10 & 0.38 & 0.20 & 49.65 & 123.00 & 0.38 & 0.24 \\
\hline
\end{tabular}

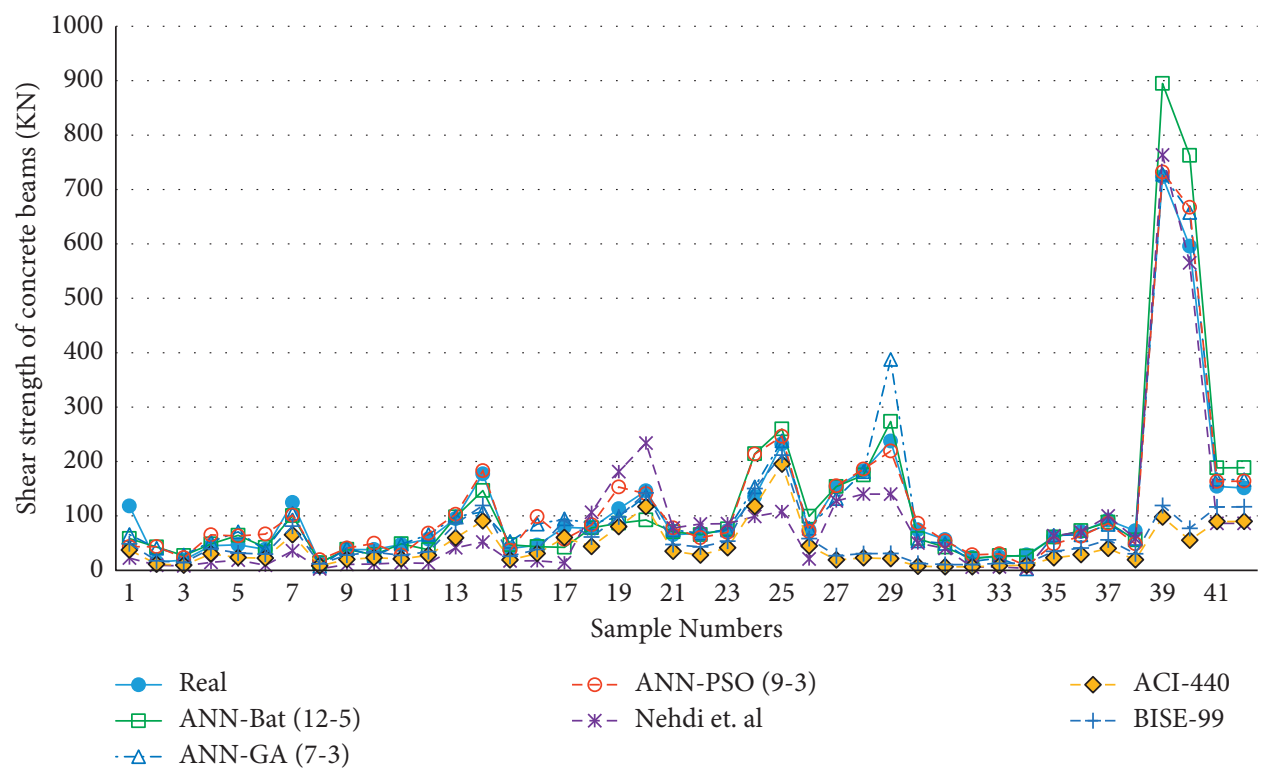

FIgURE 13: Comparison of the predictions of all models using test data.

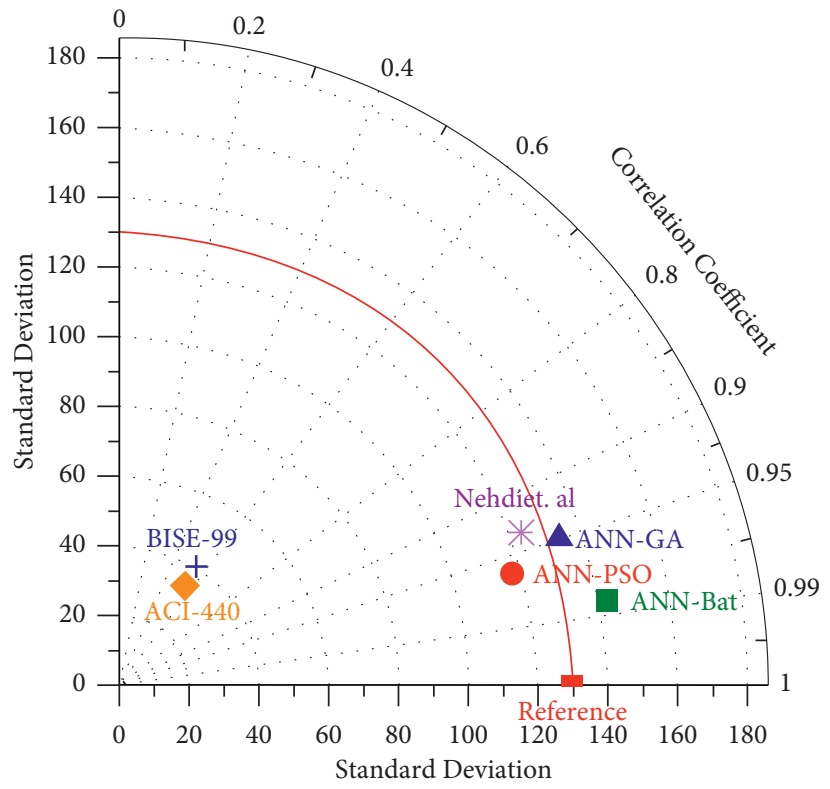

FIgURE 14: Taylor diagram visualization of model performance based on prediction results for the shear strength of concrete beams. 
TABLE 9: Final weights and bias values for the optimized ANN-BAT 2L (12-5) model 6-12-5-1.

\begin{tabular}{|c|c|c|c|c|c|c|c|c|c|c|c|c|}
\hline IW & & & & & & & & & & & & b1 \\
\hline 0.4204 & 0.2619 & 0.2213 & 0.0161 & 0.2935 & 0.1648 & & & & & & & 0.0739 \\
\hline-0.1767 & -0.0126 & 0.5506 & 0.7461 & 1.0547 & -0.2850 & & & & & & & -0.7219 \\
\hline-0.0935 & -0.8601 & 0.2501 & 0.0977 & -0.2429 & -0.5033 & & & & & & & -0.1321 \\
\hline 0.5766 & -0.2759 & 0.5217 & 0.1596 & -0.9188 & -0.7073 & & & & & & & 0.3617 \\
\hline 0.9171 & 0.1178 & -0.3768 & 0.2166 & 0.6056 & 0.7996 & & & & & & & -0.7331 \\
\hline-0.3815 & 0.9628 & 0.3432 & 0.3586 & -0.3698 & 0.1713 & & & & & & & 0.8099 \\
\hline-1.0985 & 0.2508 & -0.6516 & 0.7722 & -0.7020 & -0.0241 & & & & & & & -1.0067 \\
\hline 0.3690 & 0.9792 & 0.4658 & 0.5711 & 0.8705 & -0.4801 & & & & & & & -0.4421 \\
\hline 0.1206 & -0.2852 & 0.1240 & 1.5382 & -0.4439 & 0.1159 & & & & & & & 0.6865 \\
\hline 0.8449 & 0.9581 & 0.5333 & 0.2143 & 0.6084 & -0.2831 & & & & & & & 0.3670 \\
\hline-0.5709 & -0.5262 & 0.6664 & -0.4574 & 0.5272 & 0.6221 & & & & & & & -0.7244 \\
\hline-0.1940 & -0.4716 & 0.9008 & 0.8131 & -0.8359 & 0.1678 & & & & & & & -0.8964 \\
\hline LW1 & & & & & & & & & & & & b2 \\
\hline-0.9106 & -0.5498 & 0.1001 & 0.3170 & -0.3867 & -0.0270 & 0.2159 & 0.1310 & -0.8435 & -0.5967 & -0.0153 & -0.4711 & 0.8855 \\
\hline 0.5996 & 0.2994 & -0.8976 & -0.5387 & -0.1527 & -0.6867 & -0.7396 & -0.5912 & -1.6238 & 0.0733 & 0.2830 & 0.0238 & -0.9662 \\
\hline-0.6558 & -1.0271 & -0.8346 & -0.2157 & -0.9100 & -0.7549 & 0.0454 & 0.2270 & 0.7232 & -0.9243 & 0.1531 & -0.3032 & -0.0690 \\
\hline 0.4121 & 0.2851 & -0.0533 & 0.8826 & 0.6117 & -0.3530 & 0.6867 & -0.8073 & -0.1895 & 0.7869 & -0.2941 & 0.1125 & -0.7400 \\
\hline-0.6563 & 0.5328 & -0.2316 & 0.6435 & -0.1223 & 0.1556 & -0.4176 & 0.6846 & -0.4174 & -0.9972 & 0.3888 & 0.6416 & 0.9518 \\
\hline LW2 & & & & & & & & & & & & b3 \\
\hline 0.5901 & 1.1812 & -0.4576 & -0.4174 & -0.0902 & & & & & & & & -0.1794 \\
\hline
\end{tabular}

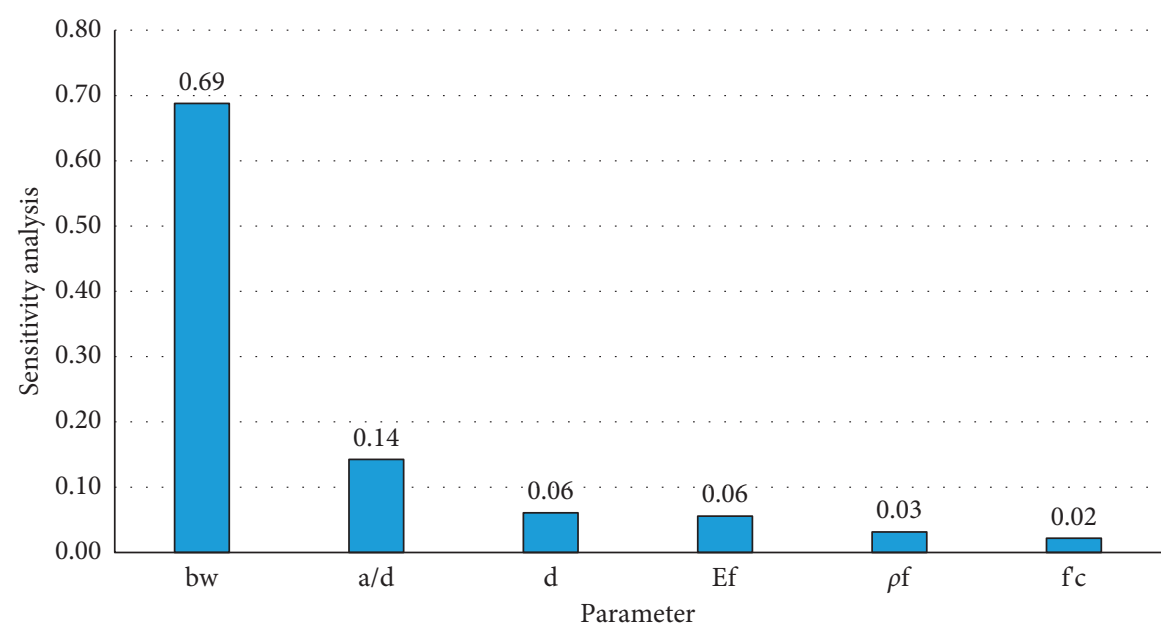

FIGURE 15: Sensitivity indices of variables for shear strength in FRP-reinforced concrete beams.

individually. Therefore, acknowledging the nature of the complex nonlinear behavior and variation of shear strength in the FRP-reinforced concrete beams in the current study, the sensitivity analysis was selected to be much more rational for investigating the impact of input parameters on the overall performance [44]. Therefore, Figure 15 shows the effect of input parameters on shear strength using sensitivity analysis. The parameter $b_{w}$ with a value of 0.69 has the most effect and the parameter $f_{c}^{\prime}$ with a value of 0.02 has the least effect on the shear strength of the concrete beams variable.

\section{Conclusion}

One hundred and forty experimental results were collected from different journal articles that predicted the concrete beams' compressive strength. The bat algorithm was employed to train the ANN models in predicting the shear strength in the concrete beams. A summary of the results is provided as follows:

(1) The ANN-Bat 2L (12-5) model offers superior prediction results than ANNs with similar topologies. The models' RMSE and VAF\% for all data were $26.43 \%$ and $96 \%$, respectively.

(2) An experimental model was presented by Nehdi et al. as a simple model to predict the shear strength in the concrete beams. Despite their acceptable results, our proposed ANN-Bat 2L (12-5) model offers superior performance.

(3) ANN based on two genetic algorithms and particle swarm optimization was trained using the same data. The best models for the two algorithms are ANN-GA 2L (7-3) and ANN-PSO 2L (9-3). Comparing the ANN-Bat 2L (12-5) model as our 
proposed model with the other two algorithms shows that the bat-optimized ANN offers better accuracy than the GA and PSO-trained ANNs. The best models in terms of importance and accuracy included PSO, GA, and the Nehdi et al. model.

(4) An ANN-Bat 2L (12-5)-based predictive model was considered to make available a ready-trained model. Since the design formulas for shear capacity should have an adequate level of safety concern, a strength reduction factor of 0.9 is proposed toward the informational model estimations.

(5) In this paper, in addition to optimization algorithms, two standard codes, including ACI-440 and BISE-99, were used to evaluate the ANN-BAT model better. The results show that the artificial neural network optimized using the bat algorithm has a very high accuracy to be used as a reliable model.

\section{Data Availability}

The datasets are available in Appendix at https://link. springer.com/article/10.1007/s11771-019-4243-z.

\section{Conflicts of Interest}

The authors declare no conflicts of interest.

\section{References}

[1] H. Naderpour, M. Haji, and M. Mirrashid, "Shear capacity estimation of FRP-reinforced concrete beams using computational intelligence," Structure, vol. 28, pp. 321-328, 2020.

[2] M. Haji, H. Naderpour, and A. Kheyroddin, "Experimental study on influence of proposed FRP-strengthening techniques on RC circular short columns considering different types of damage index," Composite Structures, vol. 209, pp. 112-128, 2019.

[3] A. K. E. Sayed, E. F. E. Salakawy, and B. Benmokrane, "Shear capacity of high-strength concrete beams reinforced with fiber-reinforced polymer bars," ACI Structural Journal, vol. 103, no. 3, 2006.

[4] M. Nehdi and H. Nikopour, "Genetic algorithm model for shear capacity of RC beams reinforced with externally bonded FRP," Materials and Structures, vol. 44, no. 7, pp. 1249-1258, 2011.

[5] M. Shahnewaz, R. Machial, M. S. Alam, and A. Rteil, "Optimized shear design equation for slender concrete beams reinforced with FRP bars and stirrups using Genetic Algorithm and reliability analysis," Engineering Structures, vol. 107, pp. 151-165, 2016.

[6] R. Perera, M. Barchín, A. Arteaga, and A. D. Diego, "Prediction of the ultimate strength of reinforced concrete beams FRP-strengthened in shear using neural networks," Composites Part B: Engineering, vol. 41, no. 4, pp. 287-298, 2010.

[7] R. Perera, D. Tarazona, A. Ruiz, and A. Martín, “Application of artificial intelligence techniques to predict the performance of RC beams shear strengthened with NSM FRP rods. Formulation of design equations," Composites Part B: Engineering, vol. 66, pp. 162-173, 2014.

[8] H. M. Tanarslan, M. Secer, and A. Kumanlioglu, “An approach for estimating the capacity of RC beams strengthened in shear with FRP reinforcements using artificial neural networks," Construction and Building Materials, vol. 30, pp. 556-568, 2012.

[9] M. Jalal and A. A. Ramezanianpour, "Strength enhancement modeling of concrete cylinders confined with CFRP composites using artificial neural networks," Composites Part B: Engineering, vol. 43, no. 8, pp. 2990-3000, 2012.

[10] R. A. Mozumder, B. Roy, and A. I. Laskar, "Support vector regression approach to predict the strength of FRP confined concrete," Arabian Journal for Science and Engineering, vol. 42, no. 3, pp. 1129-1146, 2017.

[11] E. S. Chahnasir, Y. Zandi, M. Shariati et al., "Application of support vector machine with firefly algorithm for investigation of the factors affecting the shear strength of angle shear connectors," Smart Structures and Systems, vol. 22, no. 4, pp. 413-424, 2018.

[12] J.-S. Chou, T.-P.-T. Pham, T.-K. Nguyen, A.-D. Pham, and N.-T. Ngo, "Shear strength prediction of reinforced concrete beams by baseline, ensemble, and hybrid machine learning models," Soft Computing, vol. 24, no. 5, pp. 3393-3411, 2020.

[13] J. Zhang and Y. Wang, "Evaluating the bond strength of FRPto-concrete composite joints using metaheuristic-optimized least-squares support vector regression," Neural Computing \& Applications, vol. 33, no. 8, pp. 3621-3635, 2020.

[14] O. R. Abuodeh, J. A. Abdalla, and R. A. Hawileh, "Prediction of shear strength and behavior of RC beams strengthened with externally bonded FRP sheets using machine learning techniques," Composite Structures, vol. 234, Article ID 111698, 2020.

[15] R. Kamgar, M. H. Bagherinejad, and H. Heidarzadeh, "A new formulation for prediction of the shear capacity of FRP in strengthened reinforced concrete beams," Soft Computing, vol. 24, no. 9, pp. 6871-6887, 2020.

[16] H. Naderpour, K. Nagai, P. Fakharian, and M. Haji, "Innovative models for prediction of compressive strength of FRPconfined circular reinforced concrete columns using soft computing methods," Composite Structures, vol. 215, pp. 69-84, 2019.

[17] H. Naderpour, O. Poursaeidi, and M. Ahmadi, "Shear resistance prediction of concrete beams reinforced by FRP bars using artificial neural networks," Measurement, vol. 126, pp. 299-308, 2018.

[18] Y. Cao, Q. Fan, S. Mahmoudi Azar et al., "Computational parameter identification of strongest influence on the shear resistance of reinforced concrete beams by fiber reinforcement polymer," Structure, vol. 27, pp. 118-127, 2020.

[19] S. Kar, A. R. Pandit, and K. C. Biswal, "Prediction of FRP shear contribution for wrapped shear deficient RC beams using adaptive neuro-fuzzy inference system (ANFIS)," Structure, vol. 23, pp. 702-717, 2020.

[20] M. S. Alam and U. Gazder, "Shear strength prediction of FRP reinforced concrete members using generalized regression neural network," Neural Computing \& Applications, vol. 32, no. 10, pp. 6151-6158, 2020.

[21] A. Hasanzade-Inallu, P. Zarfam, and M. Nikoo, "Modified imperialist competitive algorithm-based neural network to determine shear strength of concrete beams reinforced with FRP," Journal of Central South University, vol. 26, no. 11, pp. 3156-3174, 2019.

[22] G. Ellis, "Feed-forward," in Control System Design GuideButterworth Heinemann, Kindilington, UK, Oxford, 2004.

[23] S. Shekhar, M. B. Amin, and P. Khandelwal, Generalization Performance of Feed-Forward Neural Networks, E. B. T.-N. N. GELENBE, Ed., North-Holland, Amsterdam, pp. 13-38, 1992. 
[24] M. Fan, Z. Zhang, and C. Wang, "Optimization method for load frequency feed forward control," in Mathematical Models and Algorithms for Power System Optimization, Elsevier, Amsterdam, Netherlands, 2017.

[25] G. Ellis, "Feed-forward," in Control System Design Guide, G. B. T.-C. S. D. G. (T. E. Ellis, Ed., Elsevier, Burlington, pp. 151-169, 2004.

[26] A. Géron, Hands-on Machine Learning with Scikit-Learn and TensorFlow: Concepts, Tools, and Techniques to Build Intelligent Systems, O’Reilly Media, Inc., Newton, Massachusetts, United States, 2017.

[27] H. Simon, Neural Networks: A Comprehensive Foundation, Prentice Hall PTR Upper, Saddle River, NJ, USA, 2nd Edition, 1999.

[28] S. Haykin, Neural Networks and Learning Machines, Pearson, London, United Kingdom, 2008.

[29] M. Nikoo, M. Hadzima-Nyarko, F. Khademi, and S. Mohasseb, "Estimation of fundamental period of reinforced concrete shear wall buildings using self organization feature map," Structural Engineering \& Mechanics, vol. 63, no. 2, pp. 237-249, 2017.

[30] H. Dehghani and D. Bogdanovic, "Copper price estimation using bat algorithm," Resources Policy, vol. 55, pp. 55-61, 2018.

[31] N. Aalimahmoody, C. Bedon, N. Hasanzadeh-Inanlou, A. Hasanzade-Inallu, and M. Nikoo, "BAT algorithm-based ANN to predict the compressive strength of concrete-A comparative study," Infrastructure, vol. 6, no. 6, p. 80, 2021.

[32] M. Ali, R. C. Deo, N. J. Downs, and T. Maraseni, "Multi-stage hybridized online sequential extreme learning machine integrated with Markov chain Monte Carlo copula-Bat algorithm for rainfall forecasting," Atmospheric Research, vol. 213, pp. 450-464, 2018.

[33] E. Shadbahr, B. Aminnejad, and A. Lork, "Determining postfire residual compressive strength of reinforced concrete shear walls using the BAT algorithm," Structure, vol. 32, pp. 651-661, 2021.

[34] J. H. Drew, A. G. Glen, and L. M. Leemis, "Computing the cumulative distribution function of the Kolmogorov-Smirnov statistic," Computational Statistics \& Data Analysis, vol. 34, no. 1, pp. 1-15, 2000.

[35] J. Li and A. D. Heap, A Review of Spatial Interpolation Methods for Environmental Scientists, Australian Gvernment, Canberra, 2008.

[36] M. Najimi, N. Ghafoori, and M. Nikoo, "Modeling chloride penetration in self-consolidating concrete using artificial neural network combined with artificial bee colony algorithm," Journal of Building Engineering, vol. 22, pp. 216-226, 2019.

[37] G. J. Bowden, G. C. Dandy, and H. R. Maier, "Input determination for neural network models in water resources applications. Part 1-background and methodology," Journal of Hydrology, vol. 301, no. 1-4, pp. 75-92, 2005.

[38] M. Nehdi, H. El Chabib, and A. A. Saï, "Proposed shear design equations for FRP-reinforced concrete beams based on genetic algorithms approach," Journal of Materials in Civil Engineering, vol. 19, no. 12, pp. 1033-1042, 2007.

[39] Aci Committee 318, Building Code Requirements for Structural Concrete (ACI 318-14) and Commentary, ACI 318R-14), 2014.

[40] IStructE, Interim Guidance on the Design of Reinforced concrete Structures Using Fibre Composite Reinforcement, Inst. Struct. Eng. (IStructE), SETO Ltd., London, 1999.
[41] R. Liu and C. P. Pantelides, "Shear strength of GFRP reinforced precast lightweight concrete panels," Construction and Building Materials, vol. 48, pp. 51-58, 2013.

[42] K. E. Taylor, "Summarizing multiple aspects of model performance in a single diagram," Journal of Geophysical Research: Atmosphere, vol. 106, no. D7, pp. 7183-7192, 2001.

[43] I. Faridmehr, M. Nikoo, R. Pucinotti, and C. Bedon, "Application of component-based mechanical models and artificial intelligence to bolted beam-to-column connections," Applied Sciences, vol. 11, no. 5, p. 2297, 2021.

[44] Matlab, Mathworks, Matlab, Natick, MA, USA, 2018. 